BLS 32, No 2 2006. DOI: http://dx.doi.org/10.3765/bls.v32i2.3489

(published by the Berkeley Linguistics Society and the Linguistic Society of America)

\title{
Australian Complex Predicates
}

\author{
CLAIRE BOWERN \\ Yale University
}

\section{Introduction}

The aim of this paper is to report on the investigation of the heterogeneity of complex predicates among certain Northern Australian languages. In particular, I describe preliminary results of research into complex predicates involving a preverb (or coverb) and an inflecting light verb. ${ }^{1}$

I follow Butt and Geuder $(2001,325)$ in considering light verb constructions as a type of complex predicate which consists of a main lexical verb in combination with a lexically defective verb (of course not all complex predicates are $\mathrm{V} \mathrm{V}$ constructions, and not all V V constructions are complex predicates). I assume Butt's features of complex predicates (extracted from Butt and Geuder 2001, 323327; see also Butt 1995, 2). The definition provided by Alsina et al. $(1997,1)$ is similar: each component of the complex predicate contributes to the predicate information normally associated with a head. Thus complex predicates are 'complex' because they consist of two (or more) constituents which do the work of a single verb; in other words, the functions of the predicate are spread across multiple constituents.

\footnotetext{
${ }^{1}$ My work on Bardi was funded by AIATSIS grants G2001/6505 and G2003/6761. Many thanks to $†$ Nancy Isaac, Bessie Ejai and Jessie Sampi, who provided most of the Bardi data, for their friendship and patience in teaching me their language. The participants in Rice University's graduate syntax seminar (Spring 2006) and Beth Levin provided useful feedback. Some of the languages under discussion also show verb serialization but the scope of this paper is limited to light verb constructions, and so "complex predicate" here should be taken to refer to complex predicates of the preverb + light verb type.
} 
Many constructions fall under this definition, including serial verb constructions, restructuring predicates, and various "light verb" constructions. The most usual construction in Northern Australian languages comprises an uninflecting (or largely uninflecting) preverb and one of a small number of inflecting verbs. All the languages in question are head marking and the "inflecting" verbs function as predicates in their own right. ${ }^{2}$

In $\S 2$ I give a more detailed overview of the light verb constructions. The aim of $\S 3$ and $\S 4$ is to quantify the extent of diversity among these constructions, in order to see whether the different languages show similar syntactic behavior in their light verb constructions (and if not, how they differ, and whether it is possible to trace the source of the difference).

\section{Australian Complex Predicates}

Light verb complex predicates are found in a belt of languages across the North of Australia, from the Dampier Peninsula in the West to Arnhem Land at the eastern end of the Northern Territory. This area includes multiple genetic families, and indeed at this stage there seems to be little correlation between genetic affiliation and the presence or absence of complex predicates. A map is given in Figure 1 below.

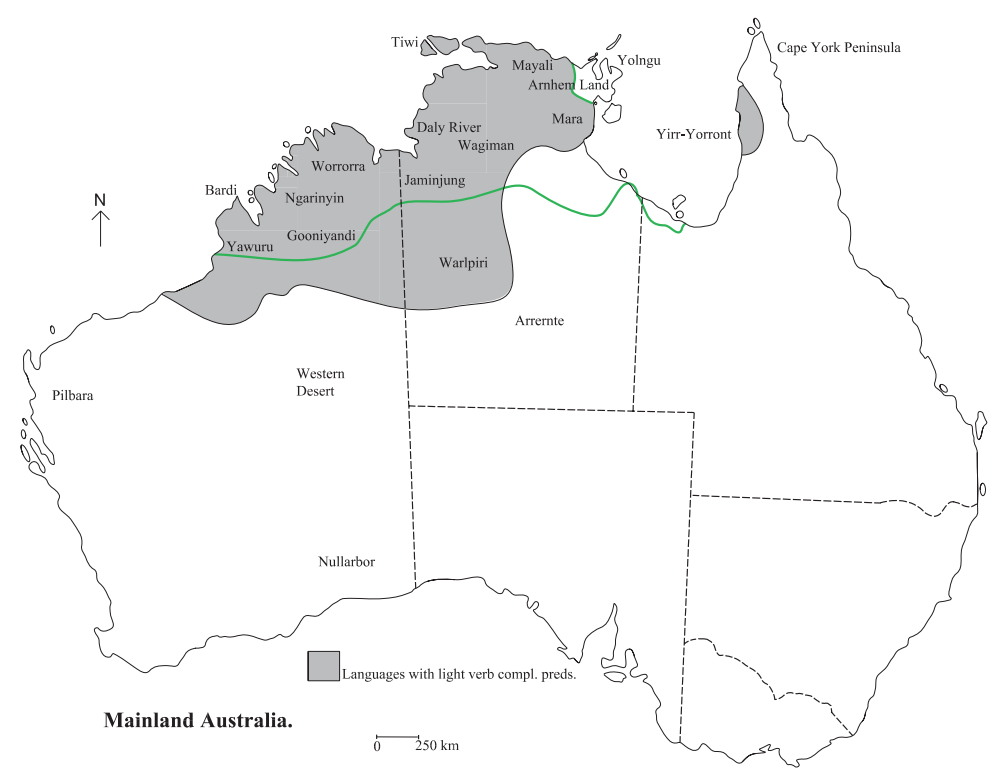

Figure 1: Map of Australia showing distribution of complex predicates

\footnotetext{
${ }^{2}$ There is an exception to this statement: in a few languages the light verbs and preverbs have univerbated and form a single phonological word. This has occurred, for example, in Gooniyandi (McGregor 1990) and Nunggubuyu (Heath 1984).
} 
The type of complex predicate under consideration is described here with reference to Bardi, a Nyulnyulan (non-Pama-Nyungan) language spoken by about 25 people on Australia's north-west coast. Complex predicates in Bardi (and other Nyulnyulan languages) comprise an uninflecting preverb which immediately precedes an inflecting verb root. ${ }^{3}$ The inflecting verb hosts agreement and tense/aspect morphology, as seen in the previous section. In Bardi the preverb cannot take any verbal or other affixes, although many (but not all) preverbs can be reduplicated. The examples in (1) provide some illustration. In (1a), the preverb garr combines with the inflecting verb -boo- to form a complex predicate meaning 'rub'. The predicate is transitive. Example (1b) shows another complex predicate, this time intransitive. The preverb roowil combines with the inflecting verb -inya- to form a predicate meaning 'walk'. Note that although glosses have been given for roowil and garr, neither item exists independently of the complex predicate construction. ${ }^{4}$

a. garr nganamboogal 'I rubbed him.'

Preverb: garr 'rub'

Inflecting verb: -boo- 'hit'

Entire predicate: 'to rub (something) to stop the pain'.

b. roowil innyagal 'He was walking.'

Preverb: roowil 'walk'

Inflecting verb: -nya- 'pick up, catch'

Entire predicate: 'to walk'

Preverbs are an open word class. Loan verbs, for example, are borrowed as preverbs and assigned an inflecting verb based on the semantics of the action denoted by the preverb. The Kriol verb boojoom 'push' (from English 'push'im'5), for example, is borrowed as a preverb into Bardi and takes the inflecting verb - $m a$ 'put', along with many other verbs that imply an action involving 'transfer'. These preverbs show the same properties of classification that the non-borrowed Bardi lexicon does (see Bowern (2004, ch. 9) for more information).

Superficially, most of the languages of Northern Australia would appear to have the same type of complex predicate construction. Compare (2) (from Bardi) with the example in (3), from Wagiman. The two languages have in common a restricted set of inflecting light verbs and open class of preverbs. They are also spoken in different parts of the country and are not demonstrably related.

\footnotetext{
${ }^{3}$ Constituent order is constant. The only material which may intervene between a preverb and an inflecting verb is a sentential clitic; these cliticize to the end of the first phonological word in the phrase.

${ }^{4}$ A transitive verb is here defined as one which may take two nominal arguments, one of which appears in ergative case. The other usually appears in the absolutive. Intransitive predicates take single absolutive argument.

${ }^{5}$ In Kriol (the English-based creole widely spoken in north-west Australia, third person singular object clitic pronouns have been reanalyzed as markers of transitive verbs. Bardi borrows Kriol transitive verbs with the transitive marker intact.
} 
(2) Lalba innyagal ginyinggi bardag moonga-ngan split 3SG-TR-'catch'-REC.PST this tree sugarbag-ALLATIVE manyan gorna jamooyoon-oong. INFIN-take-CONT well axe-INSTR

"He split the log into pieces with an axe to get the bush honey easily." (Bardi)

(3) Ngonggo-gin wayi-tjjalbu-yi weeh ngan-ya-ny // lari-leying. 2SG.GEN small-ERG vomit.PFV 3SG/1SG-do-PPFV arm-LOC

"Your baby vomited on my arm." (Wagiman)

There have been several previous descriptions of complex predicates in several Northern Australian languages, however the construction is seldom regarded as a complex predicate (or the inflecting verb equated with a light verb construction). They have been described as auxiliary + infinitive constructions, for example (Chadwick 1975), or as "verb + particle" constructions (Rumsey 1982, Merlan 1994). It is only fairly recently that the term "complex predicate" has entered the literature (cf. Schultze-Berndt 2000, Wilson 1999, Bowern 2004).

Moreover, previous comparative approaches to Northern Australian complex predicates have tended to focus on three main areas. The first is the relative order of the preverb, the light verb, and any agreement marking. For example, Dixon (2002) devotes a number of pages to the different possibilities found in various Australian languages. The second area has been dubbed the 'tightness of nexus' (e.g. SchultzeBerndt 2000, 536ff); that is, how rigid the constituency of the preverb and light verb is. Finally, there have been several discussions of the semantics of the light verb (Schultze-Berndt 2000, McGregor 2002) and its contribution to the predicate as a whole.

In this paper I instead focus on a broader range of syntactic behavior, including the determination of argument structure in the predicate and the ability of preverbs to appear without accompanying light verbs.

\section{Similarities}

Let us consider some of the properties which all these languages share. Firstly, all the constructions under consideration have two components - a morphologically complex verb which can also stand alone as a verbal predicate, and another item, here termed the 'preverb'. Examples were seen in (2) and (3) above.

The inflecting ("light") verbs which can appear in these constructions are similar to those found elsewhere in the world. The number of light verbs in a given language varies, but the inventory typically includes verbs which translate as 'do', 'put', 'sit', 'hit', 'go' and 'take'. The set of the most common Bardi and Wagiman light verbs are given in Table 1.

While the light verbs used in any given language are roughly predictable, there is a great deal of diversity in the ratio of light verbs to simple predicates. For example, the Western Nyulnyulan languages each have about 10 common light verbs, 
Table 1: Bardi and Wagiman light verbs

$\begin{array}{llll}\begin{array}{l}\text { Bardi } \\ \text {-boo- }\end{array} & \text { gloss } & \text { Wagiman } & \text { gloss } \\ \text {-ga- } & \text { hit } & \text {-bu- } & \text { hit } \\ \text {-ma- } & \text { carry } & \text {-ga- } & \text { take } \\ & \text { put } & \text {-ge- } & \text { put } \\ \text {-ni- } & \text { sit } & \text {-ma- } & \text { get } \\ \text {-ar- } & \text { spear } & \text {-ra- } & \text { be } \\ \text {-joo- } \sim \text {-di- } & \text { say, do } & \text {-ya- } & \text { throw } \\ \text {-jiidi- } & \text { go } & \text {-ya- } & \text { go }\end{array}$

another 20 or so rare light verbs, and abut 200 other simple predicates (Bowern 2004, McGregor 2002). At the other end of the scale are languages such as MalakMalak (Birk 1976) with six simple predicates, all of which also participate in light verb constructions.

In all these languages, preverbs form an open, heterogeneous word class (cf. Schultze-Berndt 2001). That is, they are a large class in dictionaries, they are frequently the vehicle for borrowing verbs into the language. See (4) for an example from Bardi.

\section{(4) Wajim inamana.}

wash 'im 3SG-TR- 'put'-REM.PST

"He/She washed it."

Preverbs appear to be a heterogeneous class in many languages. In Bardi, for example, they have diverse etymologies and may be recruited from other word classes. (5) gives some examples of Bardi preverbs which also belong to other word classes.

(5) a. Nouns

$$
\begin{aligned}
& \text { girringg 'a cough'; girringg -ar- 'to cough'; } \\
& \text { anggoorr 'tears'; anggoorr -ma- 'to mourn for someone' }
\end{aligned}
$$

b. Adjectives

ngaada 'short'; ngaada -joogooloo- 'to break in half'; rambin 'heavy'; rambin -joo- 'feel heavy'

c. Adverbs

angan 'closeby'; angan -ganyi- 'to come up close';

bard 'away'; bard - ga- 'take across'

d. Loans from other languages

boojoom 'push 'im' (Kriol); boojoom -ma- 'to push off (a boat)'; warrgam 'work 'im' (Kriol); warrgam -joo- 'to work'; 
Unfortunately we do not yet have detailed etymological data and reconstructions which would allow us to be more certain about the history of preverbs in most of the languages of Northern Australia.

\section{Differences}

Let us now turn to a few of the areas in syntax where Northern Australian languages differ. For ease of presentation, and due to space restrictions, I present only a comparison between Bardi and Wagiman here, although other languages will also be mentioned where relevant. Note also that Bardi and Wagiman are not meant to present two ends of a spectrum, merely two possibilities amongst many. All data for Bardi are from my field notes or those of Gedda Aklif; data for Wagiman are from Wilson (1999).

\subsection{Bardi Preverb conjunction and stacking}

Previous studies have described differences in Australian languages in terms of the ability of preverbs and their light verbs to be separated by intervening material (that is, in terms of the tightness of nexus between the preverb and the light verb). A related question is whether preverbs are a phrasal category in a given language, and whether they can be conjoined under a single light verb.

Australian languages differ in the extent to which they allow preverbs to be stacked with a single light verb, or conjoined. For example, in Bardi conjunction of preverbs is almost impossible, and always dispreferred even when grammatical. Each preverb normally combines with a single light verb. The example in (6) is very unusual; the preferred construction is given in (7).

(6) Bilirl agal girringg nganarij bardi.

yawn and cough 1-TR-spear-MID.PERF yesterday

'I yawned and coughed all day yesterday.'

(CB/FN: NI.3/47)

(7) Bilirl nganarij bardi agal girringgirring

yawn 1-TR-spear-MID.PERF yesterday and cough

nganarij.

1-TR-spear-MID.PERF

'I yawned and coughed all day yesterday.'

There is one case, however, where multiple preverbs are allowed with a single light verb in Bardi. That is where the first preverb marks the trajectory of the action (the most common of these is bard "off (away from speaker)"). Two examples are given in (8).

$$
\begin{aligned}
& \text { a. bard arr -joo- } \\
& \text { off go do/say } \\
& \text { 'go off' }
\end{aligned}
$$




\section{b. bard roowil -nya- \\ off walk catch \\ 'walk off'}

Let us now compare the data for Bardi to some parallel examples in Wagiman. In Wagiman it is much more common to have multiple preverbs. (9) is an example. (My understanding from Wilson (1999) is that such phrases are not common in his corpus, but they were produced spontaneously. This is in contrast to Bardi, where they never occur spontaneously apart from sentences such as (8), and the examples in (6) were only constructed by a speaker after a great deal of thought and some prompting.)

(9) Gurruwitj-yi nangh berrh la-ng.

motorcar-ERG knock down.PFV throw.PFV 3SG.throw-PPFV

"A car knocked them down."

(10) Gabarn-ma wek-ga ga-ra-n.

quickly-ASP swallow-ASP 3SG-throw-PRES

"He swallows it quickly."

(Wilson 1999, 71)

Warlpiri is another language where preverb stacking is possible, although the possibilities are more limited, and depend on the semantic class of the preverb. ${ }^{6}$

(11) kanginy- purda-nya -nyi

misperceiving- hear- perceive -CLS

ERG fail to hear ABS properly

(Nash 1982, 175)

\subsection{Preverbs as heads of phrases}

In the previous section we saw that the situations in Bardi which allowed more than one preverb per phrase were very limited. Furthermore, in Bardi it is almost impossible for a preverb to appear without an associated light verb. That is, preverbs in Bardi are not the sole heads of phrases, no matter what other head-like properties they exhibit. Two examples are given in (12) and (13). It should be noted that in the first, jirrma is probably not a preverb at all, but a noun homophonous with a preverb. The preverb status of (13) is more secure.

\section{Roowil innyij jirrma-nyarr.}

walk 3-TR-catch-MID.PERF singing-COMIT.

'He walked away singing.'

(Aklif 1990-1994, E0/11)

\footnotetext{
${ }^{6}$ For details about the limitations, see Nash (1982).
} 


\section{(13) Banyjoord gorna [bangalonngan oogool] irrjimbin=jamb poison root good reef holes-ALL/PURP scatter 3PL-die-CONT=THUS aarli. \\ fish.}

'Banyjoord poison root is used for scattering in crevices of reefs so that the fish die. (Aklif 1999)

Most preverbs do not follow this pattern, however, and instead an infinitival form of the light verb appears (that is, there is a nominalized verb phrase instead of a single preverb). (14) gives an example. In (14a), manyan is the infinitive of the light verb -(i)nya- 'catch'; (14b) is an equivalent sentence, without the infinitive. It is ungrammatical.

$$
\begin{aligned}
& \text { a. Roowil-ngan manyan gorn=amb. } \\
& \text { walk-ALL GER-catch-CONT good=THUS } \\
& \text { 'It's good to walk.' } \\
& \text { b. * Roowil-ngan gorn=amb. } \\
& \text { walk-ALL good=THUS }
\end{aligned}
$$$$
\text { (CB/FN: NI. 11/26) }
$$

Such behavior is again a difference between Bardi and many other Northern Australian languages. Other members of the same language family allow more freedom than Bardi (e.g. Yawuru; cf. Hosokawa 1991). Two examples are given here from Wagiman. In (15) we see a list of actions; note that only the first has a light verb. In (16) we have an example of an imperative.

Ngi-ya-nggi woerrkge-ma maman // garatjjin dorroh-dorroh // denh-na 1PL-go-PAST work-ASP good grass pull out-REDUP cut-ASP wirin.

tree.

"We worked well, pulling out grass, cutting trees."

(16) Gurrh-ma welin!

dig-ASP hole

"Dig a hole!"

(Wilson 1999, 73, 81)

Such examples are even more frequent in some other Northern Australian languages, for example in Jaminjung (Schultze-Berndt 2001) and Wardaman (Merlan 1994). In some languages, nearly half the verbal clauses in texts appear without an accompanying light verb. ${ }^{7}$

\footnotetext{
${ }^{7}$ It should be noted that the ability of apparently non-finite forms (preverbs) to appear without finite verbs is an interesting piece of evidence against the idea that light verbs are argument licensers; that is, that the arguments of the preverb are transferred to an item capable of assigning case and licensing them within the clause (e.g. Grimshaw and Mester 1988). I leave this point for further discussion, since I assume a unificiation analysis here and the point is immaterial to this paper.
} 


\subsection{Preverb inflection}

Although preverbs in these Northern Australian languages are typically characterized as 'uninflecting', most languages allow limited inflection on the preverbs. Bardi is unusual in allowing only reduplication; there is no other productive preverb inflection in this language (and the unproductive inflection is so rare that the meaning of the morpheme cannot be identified with any certainty). An example of reduplication is given in (17) below. Reduplication in the preverb marks iterativity or distributivity.

a. Garrjagarrja anama!

sharpen 2.IMP-TR-put-FUT

'Sharpen it!'

(NI: CB/20.6:54)

b. Bawinbawin ingirrinyagalirr goorlil. cut up-REDUP 3PL.PST-'catch'-REC.PST=3PL.OBJ turtle.

"They were cutting up the turtles."

When we compare the examples with the data for Wagiman, we again see a difference. In (18), for example, the preverb takes the negative imperative suffix (and there is no accompanying light verb) - this is the most common way to mark negative imperatives in the language. In example (19) we have an allomorph of the aspectual morpheme -ma, while in (20) the preverb is nominalized and exhibits the ablative case marker - gunda. ${ }^{8}$

Lurt-wehen danganyin!

give-NEGIMP tucker

"Don't give (them) tucker!"

(Wilson 1999, 58)

(19) Baningh-nga mu-yama?

do what-ASP 2PL-do.FUT

"What are you lot going to do?"

(Wilson 1999, 50)

Dilh-dil-may-gunda nga-nyar-ma-n lari. write-REDUP-NOM-ABL 1 SG-be tired-VERB-PREB arm

"my arm is tired from writing."

(Wilson 1999, 85)

A similar array of inflectional possibilities is to be found in Wardaman (Merlan 1994). In contrast, in Warlpiri, the only inflection allowed on preverbs is marking for trajectory. ${ }^{9}$

${ }^{8}$ According to Wilson (1999) not all speakers of Wagiman use the nominalizer in such constructions.

${ }^{9}$ Note, incidentally, that trajectory is the only category which forms doubled preverbs in Bardi; see example (8) above. 


\subsection{Preverbs, light verbs, and valency}

Finally, let us consider some of the issues involved in the specification of argument structure in Northern Australian complex predicates. As is typical in complex predicates of this type, the transitivity of the clause is determined by several different parts of the predicate. In Bardi, for example, the verbal morphology, the preverb and the inflecting verb all influence the transitivity of the predicate. (21) gives an example of the reflexive/reciprocal circumfix on the inflecting verb and its effects on argument structure; (21a) is transitive and contains the first person object marker $=($ jarr)ngay; $(21 \mathrm{~b})$ on the other hand is intransitive and exhibits a single participant. ${ }^{10}$

a. Barn injoogaljarrngay.

tell 3-PST-do/say-IMPERF-1MIN.DO

'He told me to do something.'

b. Barn ingim.inyjigal.

tell 3-PST-REFL ${ }^{-}$'do/say'-REFL 2 -IMPERF

'He thought about it.'

The choice of light verb also influences the transitivity of the predicate. In (22) and (23), for example, we see a pair of clauses which differ only in the choice of light verb. The first contains a single participant, while the second has two. In (23), oola 'water' is the subject of the clause, while in (22b), it is the direct object (Bardi is morphologically ergative; in both examples oola is in the absolutive case).

a. Boorroolboorrool oonkara oola.

boil-redup 3MIN.FUT-spear-FUT water

'The water will boil.'

b. Boorroolboorrool oonkama oola.

boil-redup 3MIN.FUT-put-FUT water

'He/She'll boil the water.

(23) a. goojaj-joo- 'to feel weak'

b. goojaj-ma- 'to make someone weak'

Finally, it is worth noting that the valency of the light verb itself is not straightforward. While monovalent light verbs always produce monovalent complex predicates, the bivalent light verbs do not always result in bivalent complex predicates. As seen from (24) below, a bivalent verb such as - $m a$ - 'put' can appear with both

${ }^{10}$ Transitivity in Nyulnyulan languages is defined by the presence or absence of direct object agreement markers, by the cases in which free nominals appear (ergative and absolutive for transitive clauses) and by the number of possible free nominals which appear in the clause. 
transitive and intransitive complex predicates. ${ }^{11}$ Further examples are given in (25) with another light verb, -(i)nya- 'get, pick up'.

-ma- 'to put' (2 obligatory arguments)

a. jiibard -ma- 'to sneak up' (1 argument)

b. niya -ma- 'to rest' (1 argument)

c. oona -ma- 'to defecate' (1 argument)

d. wajim -ma- 'to wash something' (2 arguments)

e. garboo -ma- 'to dig around something' ( 2 arguments).

-(i)nya- 'to catch, to pick up' (2 obligatory arguments)

a. ngalar -(i)nya- 'to have one's eyes open' (1 argument)

b. marrmarr -(i)nya- 'to flash' (1 argument)

c. galgooriny -(i)nya- 'to swim breaststroke' (1 argument)

d. roowil -(i)nya- 'to walk' (1 argument)

e. joony -(i)nya- 'suck something' (2 arguments)

f. bawinbawin -(i)nya- 'cut up something' (2 arguments)

The relationship between the valency of the light verb and the valency of the preverb is a source of major differences between Northern Australian languages. In some languages there is strict correspondence between the valency of the light verb and the number of arguments in the overall predicate. In Warlpiri, for example, the case frame of the clause and the number of arguments are directly inherited from the light verb; the preverb has no effect on this aspect of argument structure. We see from (26), for example, that the case frame for the complex predicate is the same as that of the inflecting verb.
a. kanginypa-nya-nyi 'ERG fail to see ABS' (nya- 'see' - ERG/ABS)
b. kanginypa-karri-mi 'ABS fail to perceive DAT' (karri- 'stand' ABS/(DAT))

In a few other languages, we see argument structure oddities of the same type that Bardi shows, with some differences. In Wagiman, for example, some monovalent light verbs may appear in transitive predicates:

Galh-ma ngi-ya-nggi-ngana garradin.

climb-asp 1pl-go-past-incl hill.

“we climbed the hill' (Wilson 1999, 161)

11 Transitive complex predicates are those where two free nominal arguments may appear, and where there are two agreement markers on the verb. The majority of such verbs have ergative/absolutive case marking and subject and direct object agreement marking. 
Wagiman does not have complex predicates in which the light verb appears to be missing an argument; all examples are cases where the preverb introduces an extra argument (that is, where a monovalent light verb participates in a transitive complex predicate).

The only other language with the same type of 'subtractive' argument structure as Bardi (where the transitivity of the clause is not predictable from preverb or light verb alone) is Jaminjung Schultze-Berndt (2000). She discusses 'dummyundergoers' of some transitive verbs, where an extra argument does not appear although it is cross-referenced in the agreement morphology.

$\begin{array}{lll}\text { Ngayin=malang bul } & \text { gani-ma bunyag. } \\ \text { meat.animal=GIVEN emerge } & \text { 3sg:3sg-HIT.PST } 3 \mathrm{dl} \text {.OBL }\end{array}$

'The animal came out to/for the two.'

(Schultze-Berndt 2000, 181)

In this sentence the prefix chunk is transitive, marking a third person singular subject acting on a third person singular object. The preverb bul 'emerge', however, licenses only one argument. (The oblique pronoun bunyag is not cross-referenced by the verb.) Schultze-Berndt explains this as a morphology/syntax mismatch (that is, that the morphological structure of the verb requires an object morpheme to be present even if it has no exponent in the syntax). The same solution is possible for Bardi too, although it requires a theory of morphology and syntax in which this is possible. $^{12}$

\subsection{Summary}

Thus we have seen that Northern Australian languages (particularly Bardi and Wagiman) differ extensively in the syntax of their complex predication. In Bardi, but not necessarily in other Australian languages, preverbs form a close-knit unit with the light verb and are strictly preverbal. There are limited possibilities for conjunction, stacking, and appearance without a light verb. That is, preverbs differ in the extent to which they head phrasal categories. Preverbs can assign $\theta$-roles in Bardi and Wagiman, but the possibilities are more limited in other languages. Preverbs affect the transitivity of the predicate and case marking of core arguments in some languages, whereas in others (such as Warlpiri) case marking is determined entirely by the light verb.

Table 2 summarizes the behavior of Bardi and Wagiman.

\section{Discussion}

From $\S 4.5$ we see that there are a number of differences between languages like Bardi versus languages like Wagiman. We have also seen that the differences are not directly correlated with the tightness of nexus between the preverb and the light verb, or the relationship between simple and complex predicates.

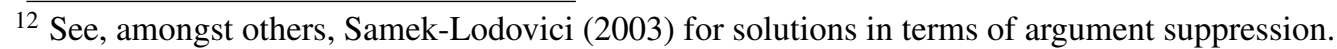


Table 2: Bardi and Wagiman compared

\begin{tabular}{lll}
\hline & Bardi & Wagiman \\
\hline Definable word class? & Yes & Yes \\
LV contributes to argument structure? & Yes & Yes \\
CV contributes to argument structure? & Yes & Yes \\
\hline Preverb stacking? & No & Yes \\
Light verb ellipsis? & No & Yes \\
Preverb ellipsis? & No & Yes \\
Aspect on preverbs? & No & Yes \\
Case on preverbs? & No & Yes (+ nom'l) \\
Valency of preverb $=$ valency of predicate? & No & Yes \\
\hline
\end{tabular}

\subsection{Analysis}

What could be the underlying cause of the difference between complex predicates in Bardi and those in Wagiman? One way to analyze this would be to extend the mechanism used by Wilson (1999) for Wagiman, Butt (1995) for Urdu, and Alsina (1997). In these works, the preverb and light verb fuse by each providing pieces of Lexical Conceptual structure or LCS (in terms of Jackendoff 1990 and related works). The following example is taken from Wilson (1999, 154-155). Under the proposal, the light verb's LCS is defective, in the sense that it lacks the full information required to be a legitimate predicate.
a. $(\uparrow \mathrm{PRED})=$ 'put $<(\uparrow \mathrm{SUBJ})(\uparrow \mathrm{OBJ})\left(\uparrow \mathrm{OBL}_{\mathrm{loc}}\right)>$ '
b. $(\uparrow$ LCS $)=\left[\right.$ Event $\operatorname{CAUSE}\left([\text { Thing }]_{A},\left[_{\text {Event }} \mathrm{GO}\left([\text { Thing }]_{A},[\right.\right.\right.$ Path $\mathrm{TO}([$ Place ]$\left.\left.\left.\left.\left.\left._{A}\right)\right]\right)\right]\right)\right]$

In (29b) the ${ }_{A}$ annotations mean that the material corresponds to an argument in the a-structure representation of the verb. The a-structures and the arguments in the LCS are linked together by a mapping of arguments to functions (e.g. CAUSE, GO, etc).

The complex predicate is composed by unifying the LCS of the light verb with the LCS of the preverb by a process of 'predicate fusion' (Wilson 1999, 136ff). The LCS of the preverb merges the LCS of the light verb wherever it can do so without violating semantic wellformedness. ${ }^{13}$

$$
\begin{aligned}
& \text { guk 'sleep' } \quad\left[\mathrm{BE}_{\mathrm{Id}}\left(\left[\mathrm{Th}_{\mathrm{Th}}\right]_{A},\left[\mathrm{AT}_{\mathrm{Id}} \text { (asleep) }\right]\right)\right]
\end{aligned}
$$

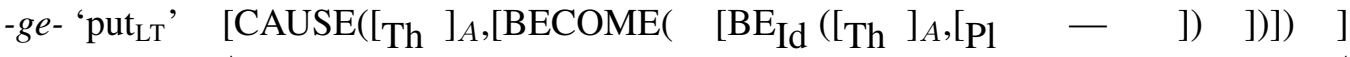

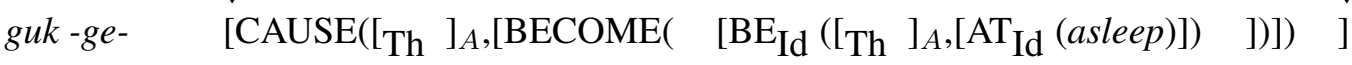

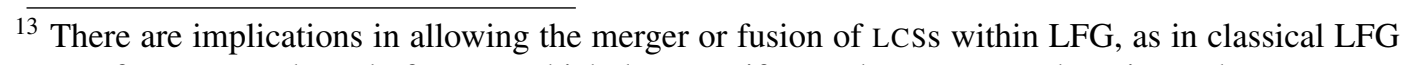
PRED features are the only features which do not unify. we do not pursue these issues here. 
(30) illustrates the merger of the LCS of the preverb guk 'sleep' with the light verb - ge- 'put'. The light verb argument structure is missing part of its predicate (the attribute of the argument of BE; this is filled by the attribute of [AT ()] in the preverb. An informal definition of predicate fusion, as illustrated above, is given below:

(31) Predicate fusion (informal)

(Wilson 1999, 166)

The LCS of a cover can fuse into any position of the LCS of an inflecting verb where it is able to unify.

Now, as noted by Wilson $(1999,154)$, the light verb provides information about the event structure of the complex predicate, while information about the argument structure comes jointly from the light verb and the preverb in some cases. As also noted above in $\S 4.2$, both the light verb (in its non-light function) and the preverb are predicational objects.

Now, in the above examples, the light verb LCS is missing certain pieces of information, but the preverb LCS is complete. Thus in Wagiman, there are many preverbs which should be complete predicates in their own right (and indeed, as we saw above, Wagiman preverbs do indeed head predicates in their own right). Now, what if we supposed that in languages with the behavior of Bardi, preverbs do not have a full LCS, but rather are missing some piece of information that licences them as full predicates? Bardi light verbs provide information about the event structure of the predicate (for example, whether it is a state, an activity, or if it involves a causer). Now, suppose that the preverb in Bardi were missing that information: preverblight verb unification would still take place, resulting in a grammatical predicate. However, the preverb would not be able to appear without a light verb, except in the case where the deficiency in LCS structure could be repaired in another way (for example, in cases where argument structure need not be specified, such as when the preverb is in a nominal position).

The main disadvantage of such an analysis is the lack of constraints on what a partial LCS might (or might not) contain. There is nothing in the literature on predicate fusion (or the type used, for example, by Wilson 1999) to limit defective LCS structures to light verbs, or to the argument structure of light verbs. Since two LCSs in a predicate may unify in any configuration that results in a grammatical structure, it is not at all clear that it would be possible to constrain defective argument structures except by stipulation. On the other hand, defective LCSs are already constrained in that the missing information must appear somewhere in the LCS of the predicate.

\subsection{Complex predicates as an areal feature}

Finally, let us briefly consider the status of complex predicates as an areal feature in Northern Australia (cf. Dixon 2002, 188 and Schultze-Berndt (2000, 532-535)). It has been claimed that complex predicates are highly borrowable and diffusible 
across linguistic boundaries - note for example that the area in Figure 1 above crosses several genetic boundaries, including that separating Pama-Nyungan and non-Pama-Nyungan languages. However, there has been no detailed work yet on the relative borrowability of preverbs as a category as opposed to, for example, nouns. That is, we have no detailed information about the processes by which complex predicates arise in different languages and what is the relative role of borrowing lexical items (such as preverbs or inflecting verbs) versus the diffusion of a particular syntactic construction. Even if we assume that the construction has spread primarily due to diffusion, we still do not know precisely what has diffused. Is it the category of preverbs? Or is it a particular consideration of preverbs and light verb? Or is it something else again? Detailed studies of the histories of individual languages and reconstruction of language families are needed before this question can be answered, and as mentioned above we lack detailed historical information for many languages and language families in Australia.

The different syntax of languages such as Bardi when contrasted with languages such as Wagiman may imply that we are not in fact dealing with the category which has diffused in the recent past, contra Dixon (2002). On the other hand, if it really is a single parameter such as a defective argument structure in preverbs, which accounts for the differences we see in these different languages, perhaps a change in type would not require a long time to be completed. However, it is not at all clear what would trigger such a change in the first place, or whether such a syntactic change is attested elsewhere in the world. ${ }^{14}$

\section{Conclusions}

In conclusion, therefore, the diversity we see amongst northern Australian complex predicates is not at all confined to the three categories usually mentioned in the literature. We see that the syntax of complex predicates is rather different from language to language, and the differences range from the phrasal status of the preverb to the argument structure determinants of different parts of the predicate. Furthermore, we see that the differences cluster and could be described in terms of an analysis using a modified form of LFG. However, there are many languages of northern Australia for which we do not have sufficient data for us to draw further conclusions.

\footnotetext{
${ }^{14}$ One place where such a change may be attested is in the Turkic languages of Central Asia, however much more work is necessary in order to determine whether the behavior of complex predicates in central Asian Turkic languages is the result of a historical change and if so, what syntactic changes were involved.
} 


\section{References}

Aklif, Gedda, 1990-1994. Bardi field notes. Unpublished notes. References are to Book/Page number.

Aklif, Gedda, 1999. Ardiyooloon Bardi ngaanka: One Arm Point Bardi dictionary. Halls Creek, Western Australia: Kimberley Language Resource Centre.

Alsina, Alex, 1997. Causatives in Bantu and Romance. In Alsina et al. (1997), 203-245.

Alsina, Alex, Bresnan, Joan, and Sells, Peter, eds., 1997. Complex predicates. Stanford, California: CSLI Publications.

Birk, D., 1976. The MalakMalak language (Daly River). Canberra: Pacific Linguistics.

Bowern, Claire, 2004. Bardi verb morphology in historical perspective. $\mathrm{PhD}$ dissertation, Harvard University, Cambridge, Massachusetts.

Butt, Miriam, 1995. The structure of complex predicates in Urdu. Stanford, Calif.: CSLI Publications.

Butt, Miriam and Geuder, Wilhelm, 2001. On the (semi)lexical status of light verbs. In Norbert Corver and Henk van Riemsdijk, eds., Semi-lexical categories : the function of content words and the content of function words, 323-369. Mouton.

Chadwick, Neil, 1975. A descriptive study of the Djingili language. Canberra: AIAS.

Dixon, R.M.W., 2002. Australian languages: their nature and development. Cambridge: Cambridge University Press.

Grimshaw, Jane and Mester, Armin, 1988. Light verbs and $\theta$-marking. Linguistic Inquiry 19(2):205-232.

Heath, Jeffrey, 1984. A functional grammar of Nunggubuyu. Canberra: Australian Institute of Aboriginal Studies.

Hosokawa, Komei, 1991. Meaning in Yawuru: A semantically oriented description of an indigenous language of the Kimberley region, Western Australia. Canberra: to be published by Pacific Linguistics. [author's Ph.D. Thesis, Australian National University].

Jackendoff, Ray, 1990. Semantic structures. Cambridge, Mass: MIT Press.

McGregor, William B., 1990. A functional grammar of Gooniyandi. Amsterdam: John Benjamins.

McGregor, William B., 2002. Verb classification in Australian languages, Empirical Approaches to Linguistic Typology, volume 25. Berlin: Mouton de Gruyter.

Merlan, Francesca, 1994. Wardaman. Berlin: Mouton.

Nash, David, 1982. Warlpiri verb roots and preverbs. Work Papers of SIL-AAB, volume A6, 165-216. Darwin: Summer Institute of Linguistics.

Rumsey, Alan, 1982. An intra-sentence grammar of Ungarinjin, north-western Australia. B86, Canberra: Pacific Linguistics.

Samek-Lodovici, Vieri, 2003. The internal structure of arguments and its role in complex predicate formation. Natural Language and Linguistic Theory 21:835- 
881.

Schultze-Berndt, Eva, 2000. Simple and complex verbs in Jaminjung. A study in event categorisation. PhD thesis, Katholieke Universiteit Nijmegen, Nijmegen, the Netherlands.

Schultze-Berndt, Eva, 2001. Preverbs as an open word class in northern Australian languages. Preverb Workshop, Nijmegen, 19th January, 2001.

Wilson, Stephen, 1999. Coverbs and complex predicates in Wagiman. CSLI Publications, Cambridge University Press.

Claire Bowern

Department of Linguistics

Yale University

370 Temple St, Room 204

PO Box 208366

New Haven, CT 06520-8366

claire.bowern@yale.edu 